\title{
GEOGRAPHICAL SHIFTING OF DEEP WATER WAVE DATA BASED ON JONSWAP METHOD
}

\author{
Giuseppe Roberto Tomasicchio ${ }^{1}$, Federica Dattilo ${ }^{2}$, Giuseppe Barbaro ${ }^{2}$, \\ Giandomenico Foti ${ }^{2}$, Felice D'Alessandro ${ }^{1}$, and Francesco Ligorio ${ }^{1}$
}

\begin{abstract}
The present paper proposes a new method to increase the number of sources of meteo marine information for the analysis of professionals and researchers in coastal and offshore engineering. The new method is mainly based on the actual geographical distance between a real and a virtual buoy and the dependence of the sea states on the characteristics of the wave development conditions; in fact, it mainly depends on the effective positions of the two locations, their geometric distance apart, and on the difference between the exposure of the point where the virtual buoy has to be located (S) with respect to the point of direct observation (O). It offers advantages compared to the traditional methods currently used; in fact, among the others, it is suitable for any sea condition: duration/fetch limited or fully arisen sea. The proposed method has been verified using data from buoys of the Mediterranean Sea (Italian and Spanish) and of the Atlantic Sea (Spanish) under different sea conditions. In particular, the time-series with a variable duration from a minimum of 2 up to a maximum of 7 years have been adopted. Use of the model is presently limited to deep water conditions. The verification, conducted without the need for any calibration, resulted positive.
\end{abstract}

Keywords: wave forecast, geographical shift, wave climate, wave data, significant wave height, fetch length, time series, sea condition, limited or fully arisen, virtual buoy.

\section{INTRODUCTION}

The design of any coastal and offshore structure requires the knowledge of the deep water wave climate which represents a basic information to select the geometry and dimensions of an offshore structure, to determine the wave agitation in a harbor, or to forecast the morphodynamic evolution of the shoreline (Barbaro et al., 2013).

At present, in Italy, professionals and researchers of maritime Hydraulics consider the public set of data at the buoys of the National wave measurement network (RON, www.ispra.it), which was started in 1989 with 8 buoys, and increased to 15 from 1999 to 2007 at different times, and which stores the main features of the wave agitation (significant wave height $H_{S}$, dominant period $T_{P}$ and direction $\theta$ ) in deep water conditions. The data, once processed according to statistical or spectral analysis, have to be propagated in the vicinity of the marine structure. The present number of RON buoys is insufficient to cover the about 7,500 km long Italian coastline, even when taking into consideration some existing buoys working as Regional Networks (ROR); as a consequence, not rarely, it is hard to determine the wave climate at some locations. This problem not only concerns Italian coasts and can be can easily considered diffuse to those countries with a limited coverage of buoy or wind data.

There are several methods in the literature to assess the offshore wave climate. The first significant contribution was provided by Hasselmann (1973) who analyzed the wind and swell waves described in the project JONSWAP (Joint North Sea Wave Project). Hasselmann (1975), by carrying out investigations on the spectral energy balance and analyzing non-stationary conditions of wind, observed that the invariance of the spectral shape is not limited to a uniform wind fetch in limited conditions, but, on the contrary, can be applied to a wind capable of generating a wave motion with significant increasing height. This property has been used in a wave prediction model estimating the wave growth from the wind blowing on the sea but lacking a propagation of swell waves model. The work by Hasselmann (1975) is described in the "Shore Protection Manual" (USACE 1984): it gives a widely used procedure for the estimation of the significant wave height, $H_{S}$, and the peak wave period, $T_{P}$, for given fetch length, wind speed and duration of the storm (referred to as the SPM or Jonswap method). The basic reasoning was that the increase in the height of the wind waves is the result of an energy flux of the air above the water surface at the given field. Most of the theories concerning the development of waves up to that time considered that the energy input depends on the surface stress, which is highly dependent upon wind speed and other factors that describe the atmospheric boundary layer above the waves. The winds used for wave forecasts are normally obtained either from direct observations over the fetch or by estimates based on weather maps.

The Hasselmann's study was the initial point of research for different authors, among which of particular importance was Smith (1991) who, based on the work of Donelan (1980), arisen and applied the NARFET model which is capable of determining the wind induced wave conditions under the fetch limited condition, taking into account the complexity of the geometry of the fetch that is not considered in the SPM method.

De Girolamo and Contini (1998) estimated the characteristics of wave condition $\left(H_{S}\right.$ and $\left.T_{P}\right)$ with a geographical shifting technique based on the relationship between the effective fetches of the original and transposition locations. Use of the method is restricted to the fetch limited condition, solely.

${ }^{1}$ University of Salento, Engineering Department, Ecotekne, via Monteroni - 73100 Lecce, Italy.

${ }^{2}$ Mediterranea University of Reggio Calabria, DICEAM Department, Via Graziella, 89124, Reggio Calabria, Italy. 
Cavaleri and Sclavo (2006) considered three sources of long-term wind and wave data available in the Mediterranean Sea: numerical models, satellites and buoys. Use of the overall information was made to obtain calibrated decadal time series at a large number of points, distributed at $0.5^{\circ}$ intervals. The accuracy of the three sources was discussed and the errors that affect the accuracy of the final results were pointed out.

The aim of the present paper is to propose an efficient and reliable geographical shifting procedure to accurately estimate the wave climate in the areas where no buoys are located, even in the case of not limited fetch. In particular, a Geographical Shifting Model ("GSM") is proposed based on the JONSWAP method (USACE 1984; Kamphuis, 2000) and the assumption of homogeneous initial wind measurement conditions at the locations of observation (in which there is a real buoy) and of geographical shift (where the presence of a virtual buoy is assumed). The procedure is easy to use and based on geometric and intuitive geographical considerations: it uses the geographical distance between the two locations and considers the dependence of the characteristics of the sea state on the conditions of wave development (for a fully arisen sea and a duration or fetch limited sea).

\section{DESCRIPTION OF THE NEW PROCEDURE}

The input data are: an historical set of observed wave conditions where the buoy is located (origin), the fetch length at the location of origin, the distance along the sea, $d$, evaluated for each direction, between the origin and the place where the virtual buoy is located $(S)$. The reasoning proposed in the method is geographical, geometrical and intuitive. Figure 1 shows the successive steps to apply the procedure: (1) a segment between the origin $(O)$ and virtual buoy is assumed $(S)$ is drawn; (2) a circle with ray $\overline{O S}$ is drawn and the orthogonal to $\overline{O S}$ passing through $O$ is considered allowing to give a positive (at the $S$ side) and negative (a the $O$ side) sign to the 4 quadrants ; (3) for a given incoming direction, the orthogonal from $S$ to the given direction is drawn and $d$ is determined as the length of the segment between $O$ and the intersection between the orthogonal and the direction. The value of , $d$ represents the distance, in terms of fetch length, between $O$ and $S$. In general, the location of $O$ (real buoy) acts as the central point, and for each of the possible directions to be taken into consideration, a value of,$d$ can be determined.

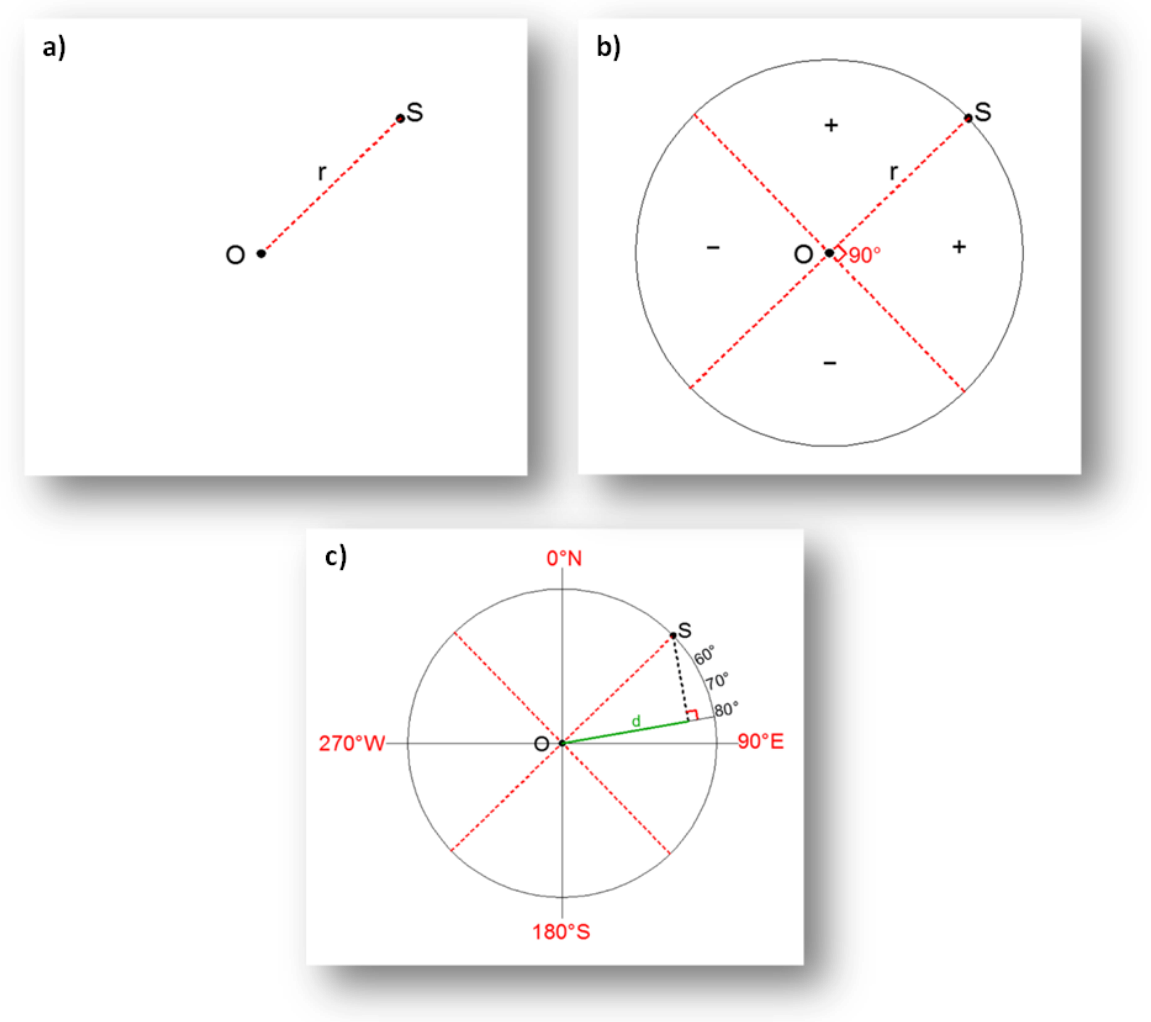

Fig. 1 - (a) Definition of $\overline{\mathrm{OS}}$; (b) identification of positive and negative areas; (c) determination of the distance, $d$ : the figure shows an example of geometrical determination of , $d$ in green, for the $80^{\circ} \mathrm{N}$ incoming direction. 
It can be observed that the same value of $d$ can be obtained for two opposing wind directions. Consequently, once $d$ is determined, a sign has to be given to each of the four quadrants: two of which will give a positive contribution (those at the $S$ side) and two of which will give a negative contribution (those at the $O$ side).

Under the assumption that the location where the observed sea condition data have to be shifted (virtual buoy) is characterized by the same wind event which generated the observed data (real buoy), the procedure is as in the following.

For given values of the significant wave height, $H_{S}$, and geographical fetch length, $F_{g e o}$, Eq. (1.1) and Eq. (1.2) allow to determine the wind $U_{a}$ (wind-stress), for the case of limited or fully arisen sea, respectively.

$$
\begin{array}{ll}
H_{s}=0.0016 \frac{U_{a}{ }^{2}}{g} \sqrt{\frac{g F_{g e o}}{U_{a}^{2}}} & \text { limited sea; } \\
H_{s}=0.2433 \frac{U_{a}{ }^{2}}{g} & \text { fully arisen sea; }
\end{array}
$$

The duration of the storm condition, $t_{r, O}$, at the origin is calculated as:

$$
\begin{array}{ll}
t_{r, O(\text { lim })}=68.8 \frac{U_{a}}{g}\left(\frac{g F_{g e o}}{U_{a}{ }^{2}}\right)^{2 / 3} & \text { limited sea; } \\
t_{r, O(\text { fas })}=7.15 * 10^{4} \frac{U_{a}}{g} & \text { fully arisen sea; }
\end{array}
$$

The sea conditions (limited or fully arisen) at the origin are assessed.

The value of the wind speed, $U$, is determined as:

$$
U_{a}=0,71 U^{1,23}
$$

The duration of the storm at the location where the virtual buoy is located $(\mathrm{S})$ is determined for both limited and fully arisen sea conditions:

$$
\begin{array}{ll}
t_{r, S}=t_{r, 0(\mathrm{lim})}+\frac{|d|}{U} & \text { limited sea; } \\
t_{r, S}=t_{r, 0(\text { fas })}+\frac{|d|}{U} & \text { fully arisen sea; }
\end{array}
$$

The sea condition (limited or fully arisen) at the virtual buoy is assessed.

A fictitious fetch $F_{f i c t, S}$, at the virtual buoy location is calculated using the following relationship:

$$
F_{f i c t, S}=F_{g e o, S}+d
$$

where $\mathrm{d}$ assumes positive or negative value depending on the sector of origin.

The significant wave height at the virtual buoy $(S)$ is obtained by the following equations:

$$
\begin{array}{ll}
H_{S, S(\text { lim })}=0.0016 \frac{U_{a}^{2}}{g} \sqrt{\frac{g F_{\text {fict }, S}}{U_{a}{ }^{2}}} & \text { limited sea at both locations } \\
H_{s, S(\text { fas })}=0.2433 \frac{U_{a}{ }^{2}}{g} & \text { fully arisen sea at both locations } \\
H_{S, S}=\frac{H_{S, S(\text { lim })}+H_{S, S(\text { fas })}}{2} & \begin{array}{l}
\text { if the sea condition is different at the two } \\
\text { locations }
\end{array}
\end{array}
$$




\section{ADOPTED OBSERVED DATA}

In order to verify the new method, the data from the Italian buoys network (RON) and from the Spanish buoys network have been adopted.

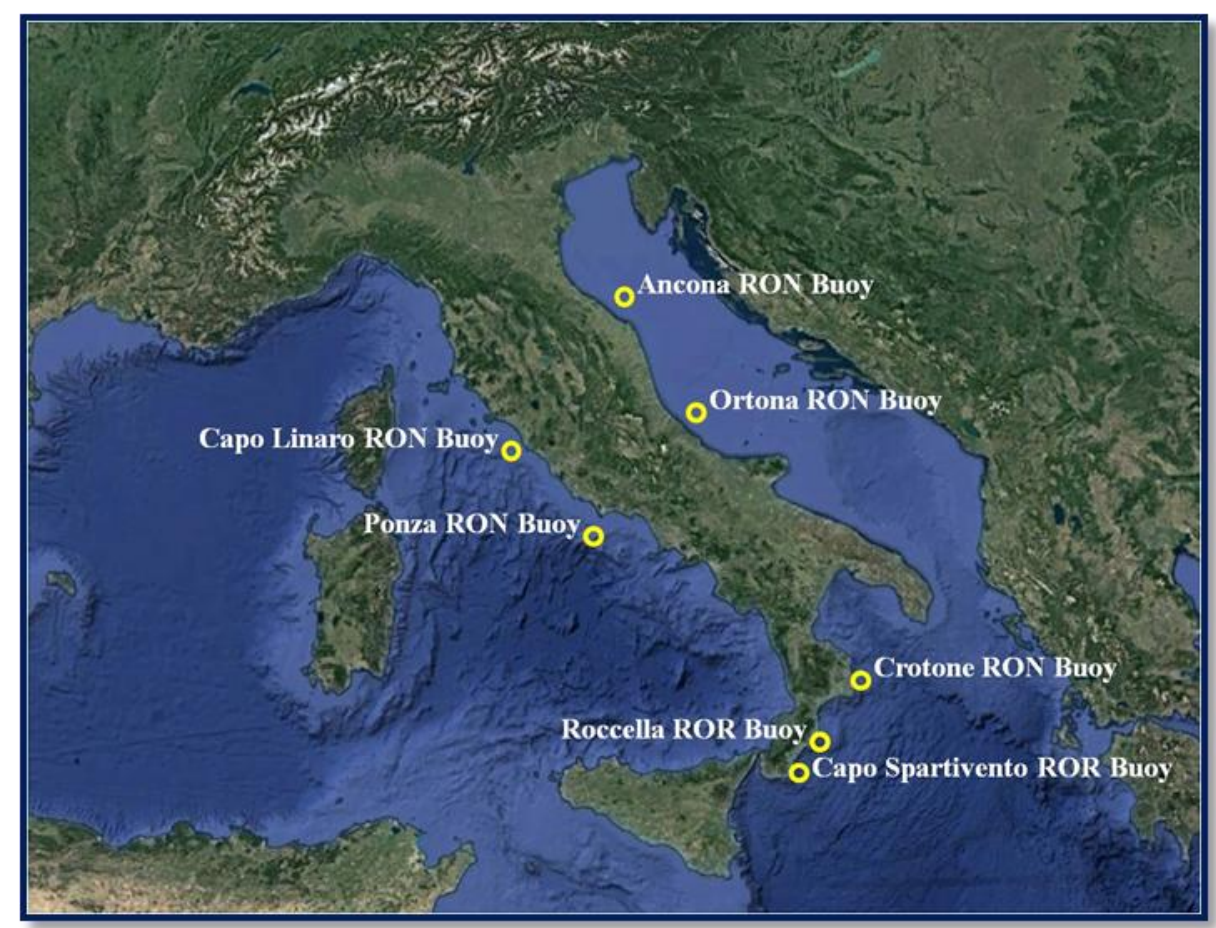

Fig. 2 - Adopted Italian buoys.

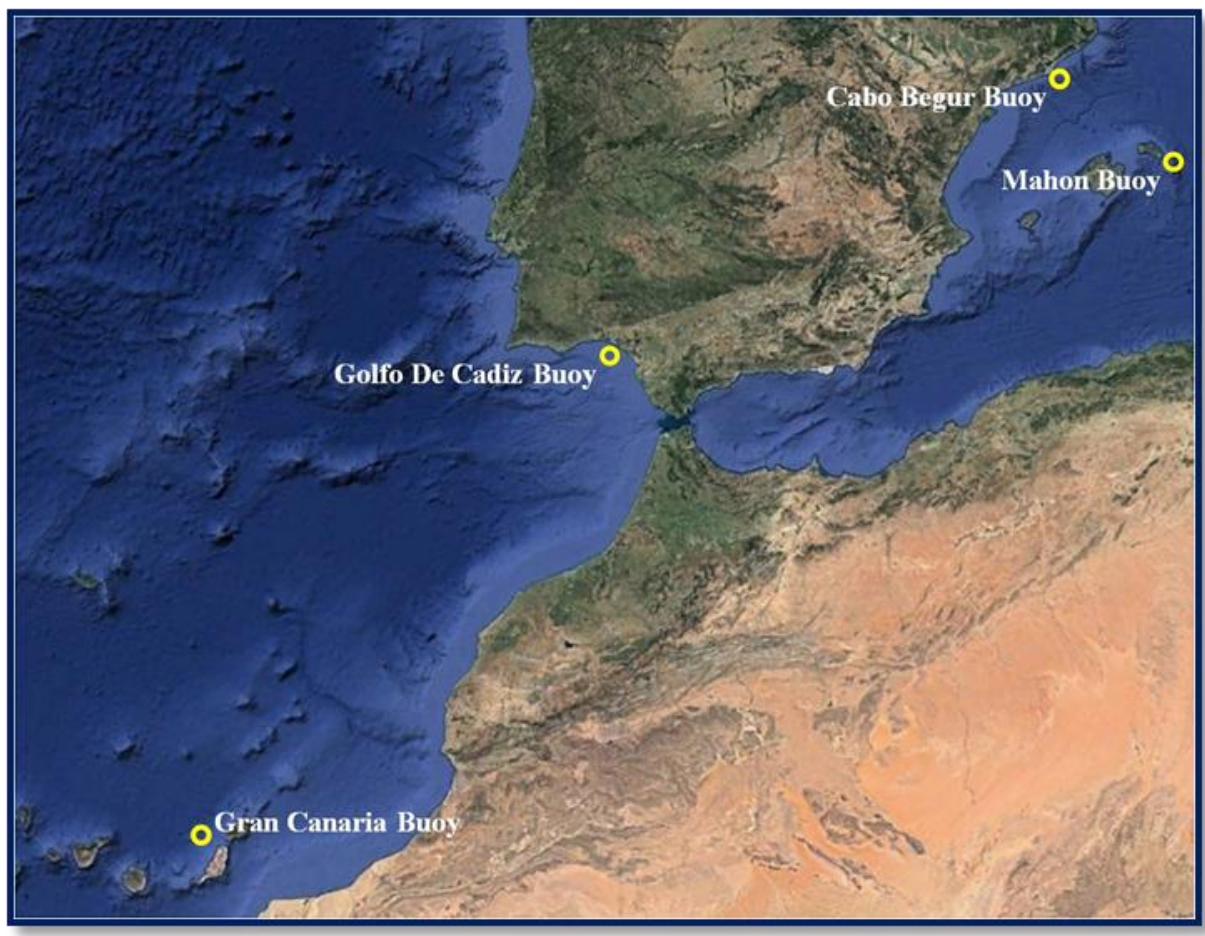

Fig. 3 - Adopted Spanish buoys.

The RON buoys are displaced at depths of about $100 \mathrm{~m}$ and, since 1989, determine the values of:

- $H_{S}$ (meters) significant wave height;

- $T_{P}$ (second) peak period; 
- $T_{m}$ (seconds) mean period;

- $\theta$ (degrees to $\mathrm{N}$ ) mean wave propagation direction;

- $E(w)$ spectral density of energy or frequency spectrum;

- $E(w, \theta)$ directional spectrum;

- $\quad$ SPREAD (directional dispersion parameter);

- Asymmetry (skewness) of the water surface elevation.

Figure 2 shows the position of the considered RON buoys of Ancona, Ortona, Crotone, Ponza, and Capo Linaro and of the Calabria region buoys network. Figure 3 shows the position of the considered Spanish buoys of Cabo Bagur, Mahon and Golfo de Cadiz.

\section{VERIFICATION OF THE NEW METHOD}

The proposed geographical shifting method has been verified with reference to sets of data directly observed at two real buoys displaced within a homogeneous sea area (Goda 2004, Gencarelli et al. 2006). In the following, the verification process is reported for the different couples of wave buoys which have been considered.

\subsection{Ponza and Capo Linaro}

Capo Linaro and Ponza buoys fall within the homogeneous area of the Tyrrhenian Sea (Gencarelli et al. 2006). The GSM method aims to shift the wave information from the offshore buoy RON Ponza $(O)$ to a virtual offshore buoy at Capo Linaro $(S)$. The verification has been limited to consideration of two years of observations (2004-2006) solely and has been based on the comparison of the calculated data at the virtual buoy at Capo Linaro with the contemporary directly observed data at the same location.

It was found a fair good agreement between the shifted values of the significant wave height, $H_{S}$, and the directly observed $H_{S}$ at the Capo Linaro RON buoy. As an example, Figure 4, referring to a 60 hours storm $\left(248^{\circ} \mathrm{N}\right.$ dominant direction), shows that the calculated values of $H_{S}$ accurately follow the trend of the directly observed data. Figure 5 shows a fair agreement even for a larger range of time (nearly 1000 hours).

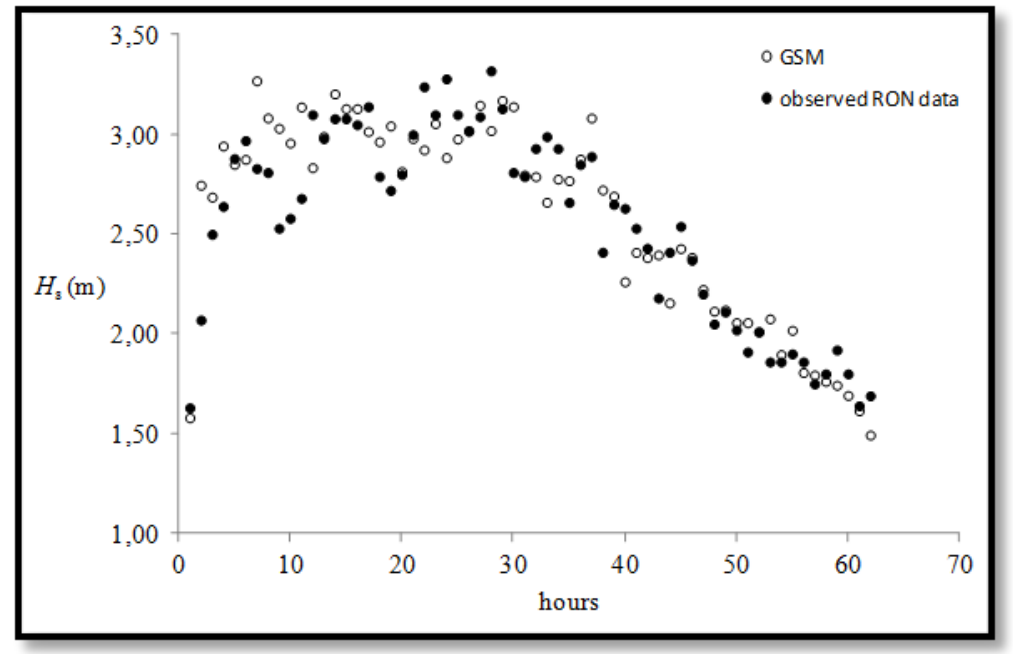

Fig. 4 - Observed $(\bullet)$ vs. shifted $(\circ) H_{S}[\mathrm{~m}]$ values.

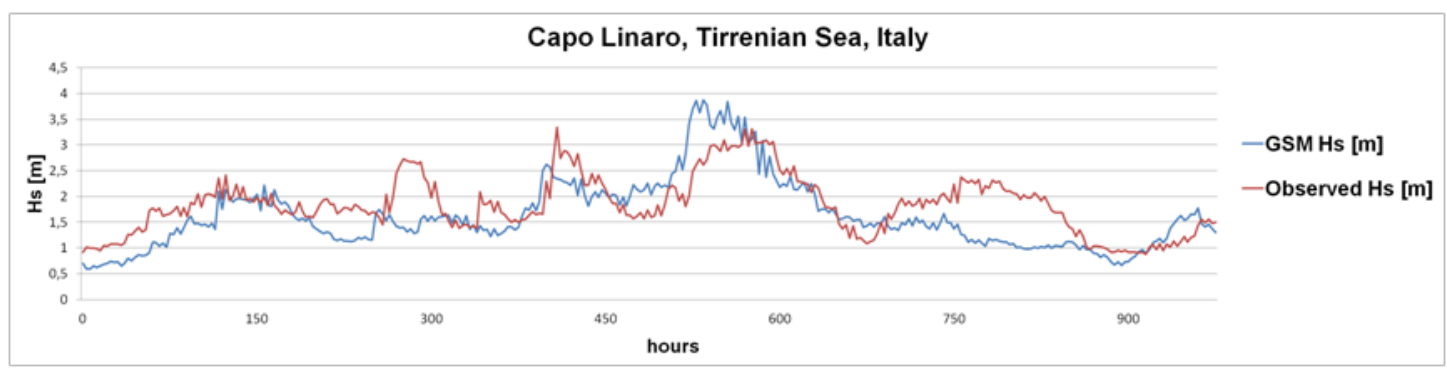

Fig. 5 - Capo Linaro, Ionian Sea, Italy: observed (-) vs. shifted $(-), H_{S}[\mathrm{~m}]$ values. 


\subsection{Ortona and Ancona}

The verification has been conducted for two locations in the Adriatic Sea: Ortona and Ancona (Figure 3). As in the previous case, Ancona has been assumed as the location where to shift $(S)$ the $H_{S}$ values which have been recorded at the Ortona buoy $(O)$. The calculated values at Ancona have been compared with the observed ones. Figure 6 shows that the calculated and observed values of $H_{S}$ (nearly 9000 hours).

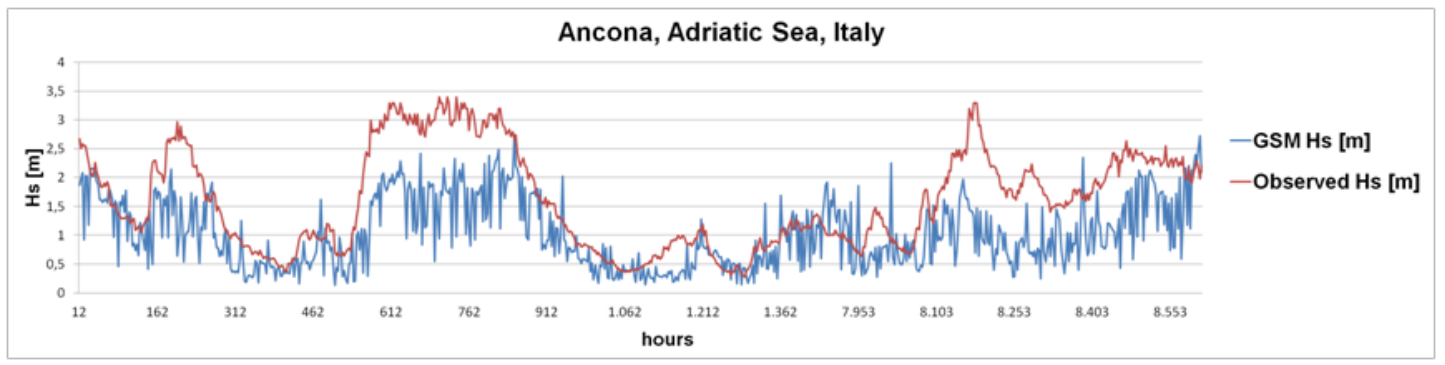

Fig. 6 - Ancona, Adriatic Sea, Italy: observed (-) vs. shifted (-), $H_{S}[\mathrm{~m}]$ values.

\subsection{Ionian Sea}

The verification has been extended to the Ionian Sea area which is characterized by large fetches and very intense and frequent winds. The only RON buoy in the area is located at Crotone. Two additional buoys in the area belong to the Calabria regional network (ROR) and are located at Capo Spartivento and Roccella Ionica. The new method was firstly applied for Capo Spartivento and Roccella Ionica, which are geographically close, and afterward for Crotone and the two mentioned locations.

\section{First case study}

Capo Spartivento has been assumed as the origin and Roccella Ionica as the virtual buoy; the comparison has considered three years of data (2003-2006). Figure 7 shows two extractions from the entire time series. Again, in this case a fair agreement has been found for all the historical set of data. A possible reason is the geographical proximity of the two considered which drives to observe that the closer are the two locations, the larger is the reliability of the method.

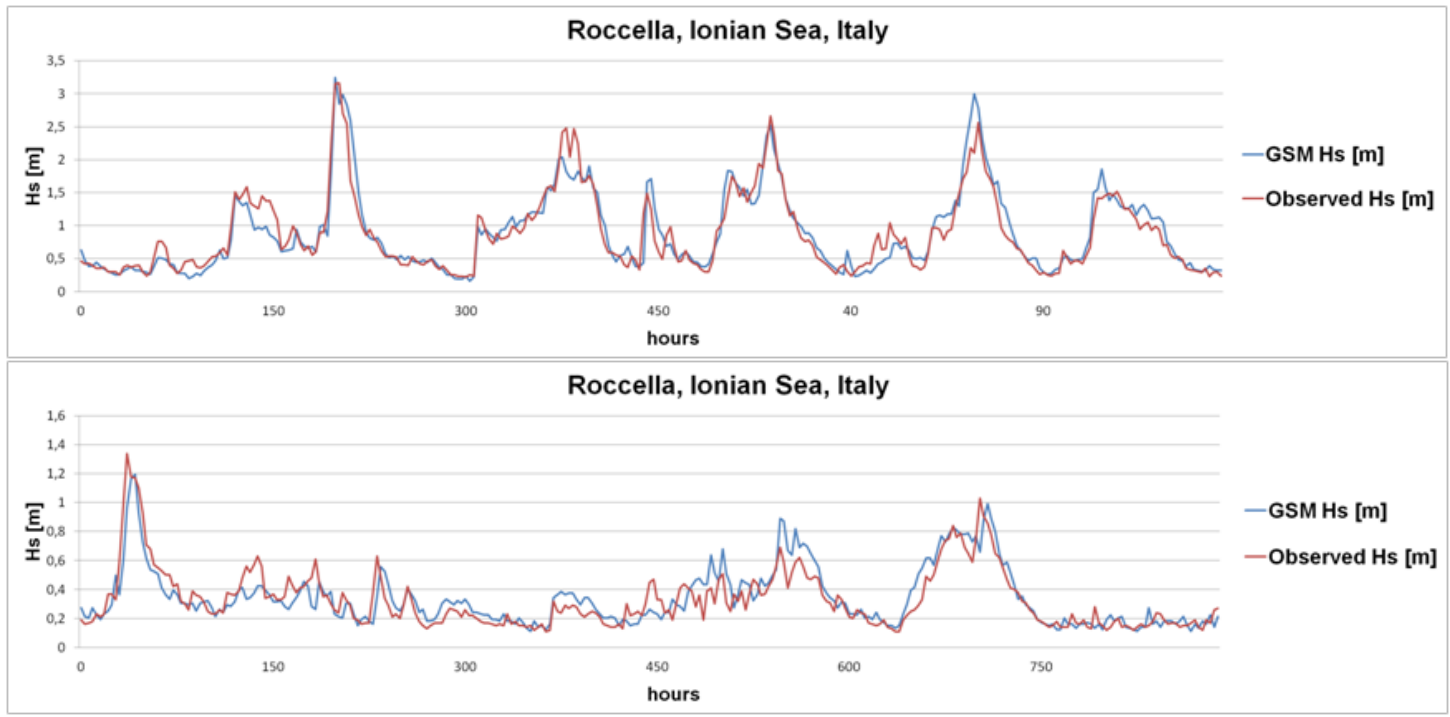

Fig. 7 - Roccella lonica, lonian Sea, Italy: observed (-) vs. shifted $(-), H_{S}[\mathrm{~m}]$ values.

\section{Second case study}

For the second case, Crotone (RON) has been assumed as the origin and its information on $H_{S}$ have been shifted to both Capo Spartivento and Roccella Ionica, for a period of two years (2003-2005). Also for this case, use of the method results in a fair agreement between observed and calculated values at the two virtual buoys at Capo Spartivento and Roccella Ionica (Figures 8 and 9). 


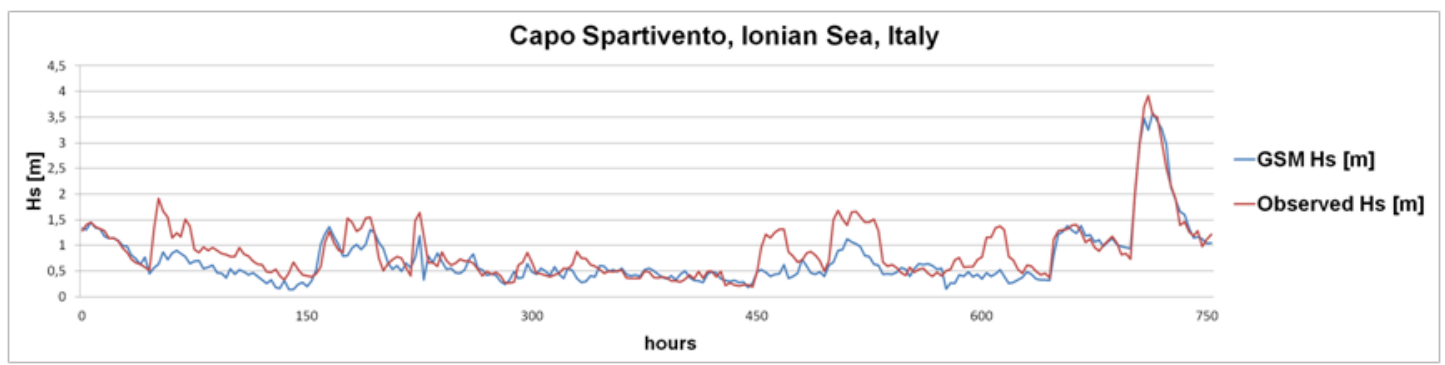

Fig. 8 - Capo Spartivento, Ionian Sea, Italy: observed (-) vs. shifted (-), $H_{S}[\mathrm{~m}]$ values.

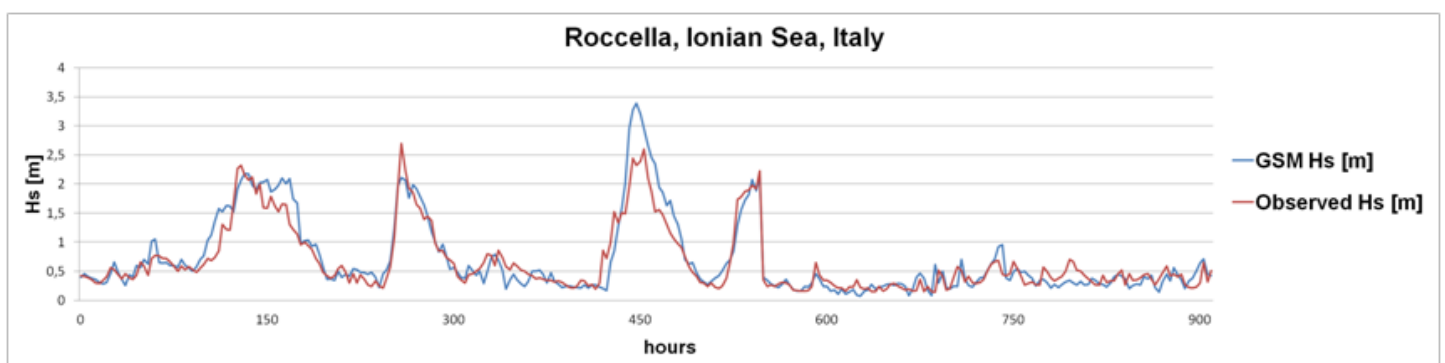

Fig. 9 - Roccella, Ionian Sea, Italy: observed (-) vs. shifted (-), $H_{S}[\mathrm{~m}]$ values.

\section{Third case study}

The third case study intends to compare the results which are obtained at Crotone $(S)$ when assuming two different origins: Capo Spartivento $\left(O_{-} 1\right)$ and Roccella Ionica $\left(O \_2\right)$ for two years (2003-2005). The results have shown two key features of the new method: the first is the dependence of the method on the distance between the locations under consideration; the second is related to the exposition of the real buoy and of the virtual buoy. In fact, Capo Spartivento $\left(O_{-} 1\right)$, compared to Roccella Ionica $\left(O_{-} 2\right)$, is more distant from Crotone and results more exposed to the large fetch from the SW. Figures 10 and 11 show the observed $\left(O_{-} 1\right.$ and $O_{-} \_$, black and blue, respectively) and shifted $\left(S\right.$, red) $H_{S}$ values. When considering the comparisons $O \_1$ vs. $S$ and $O \_2$ vs. $S$, it can be observed that in the latter the shifted $H_{S}$ values at Crotone result slightly underestimated.

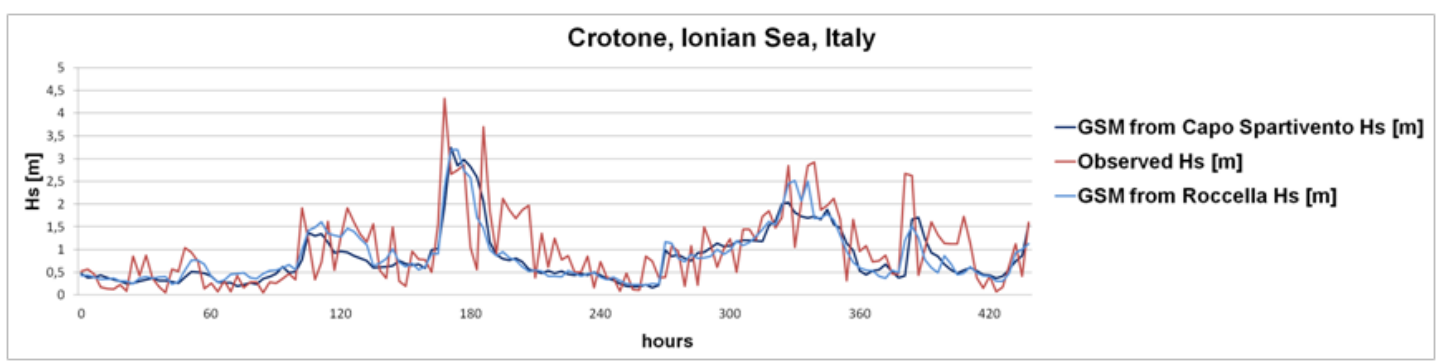

Fig. 10 - Crotone, Ionian Sea, Italy: observed (-) vs. shifted from Capo Spartivento (-) and shifted from Roccella $(-), H_{S}[\mathrm{~m}]$ values.

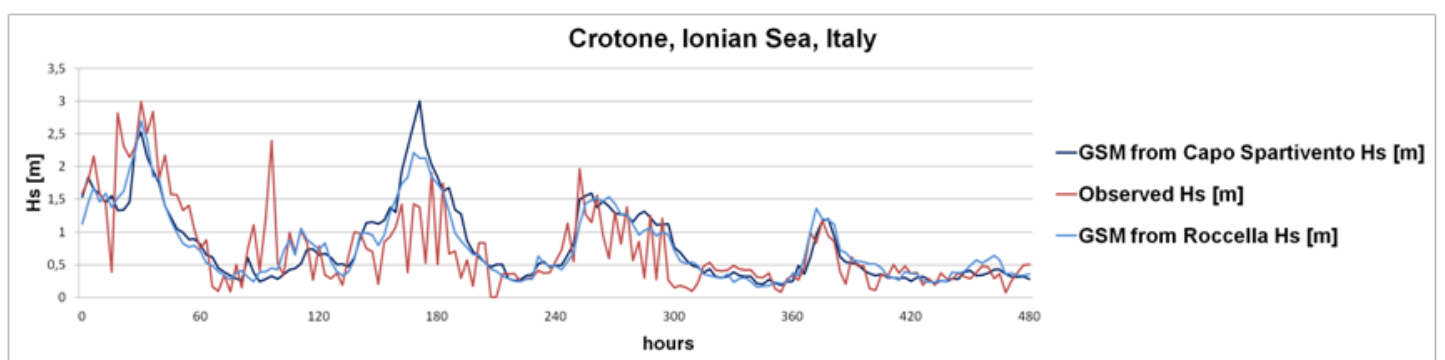

Fig. 11 - Crotone, Ionian Sea, Italy: Observed (-) vs. shifted from Capo Spartivento (-) and shifted from Roccella $(-), H_{S}[\mathrm{~m}]$ values.

This makes clearer the dependence of the reliability of the results on the geographical distance between the two locations and on the similarity of their exposure. Comparing the results from the three case studies, it can be said that the best range of applicability of the method is within a radius of some tens of kilometers from the place of origin (about $60 \mathrm{~km}$ ), a distance that can also double up without significant loss of quality of the final result. 


\subsection{Spain - Mediterranean Sea}

The method has been further verified with reference to data provided by the Spanish wave measurement network.

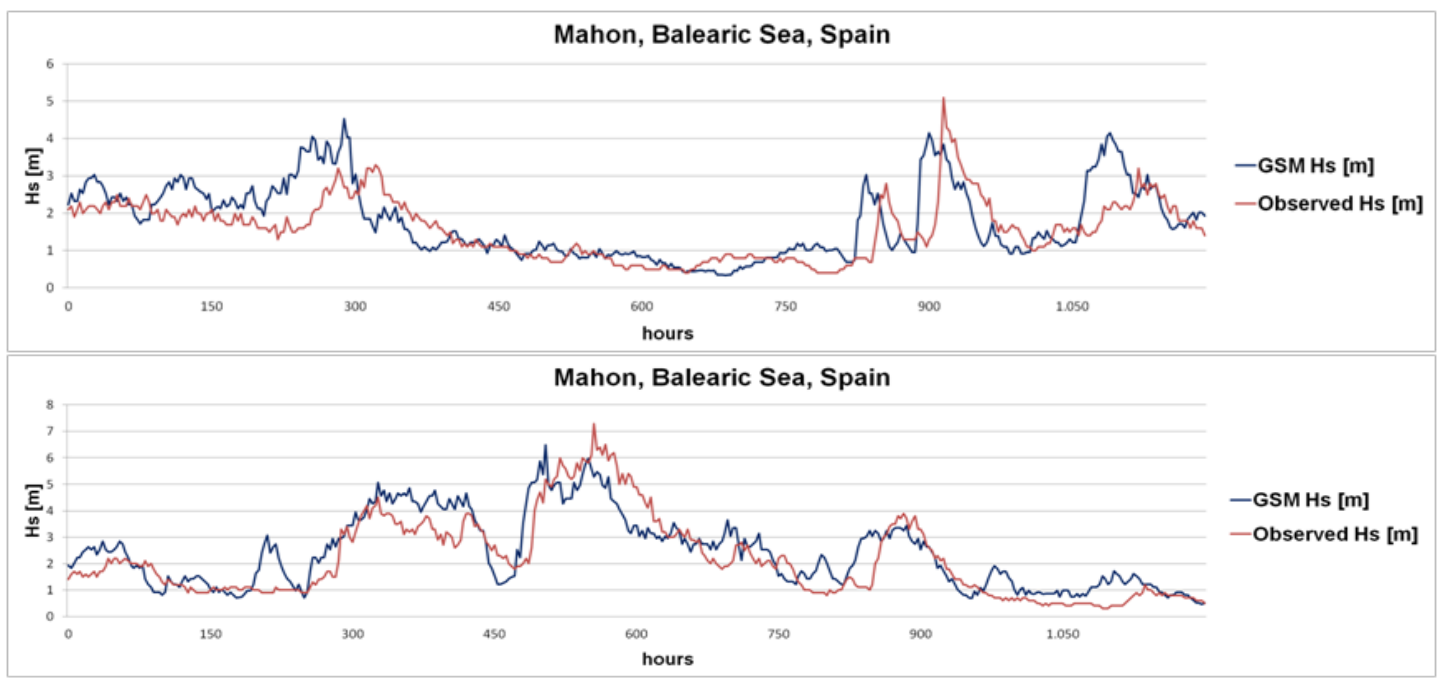

Fig. 12 - Mahon, Balearic Sea in the Mediterranean Sea, Spain: observed (-) vs. shifted $(-), H_{S}[\mathrm{~m}]$ values.

In particular, the two buoys at Cabo Begur and Mahon have been considered: the first as place of origin and the second as a place of shifting, for a six years long set of historical data (2004-2010). The verification has also performed by inverting the place of observation with that of shifting; the obtained results overlapped those from the first verification. Figure 12 shows two extractions from the comparison between the data obtained with the new method (blue) and the observed ones (red).

\subsection{Spain - Atlantic Ocean}

The Spanish wave buoys in the Atlantic Ocean data have been used as a fifth verification case; the data refer a period of seven years (2003-2010). The locations were chosen for their similar characteristics, assuming Golfo De Cadiz as the real buoy and Gran Canaria (Fig. 14b) as the virtual one. Figure 13 shows two extractions of the comparison between the data obtained with the new method (blue) and those observed (red).

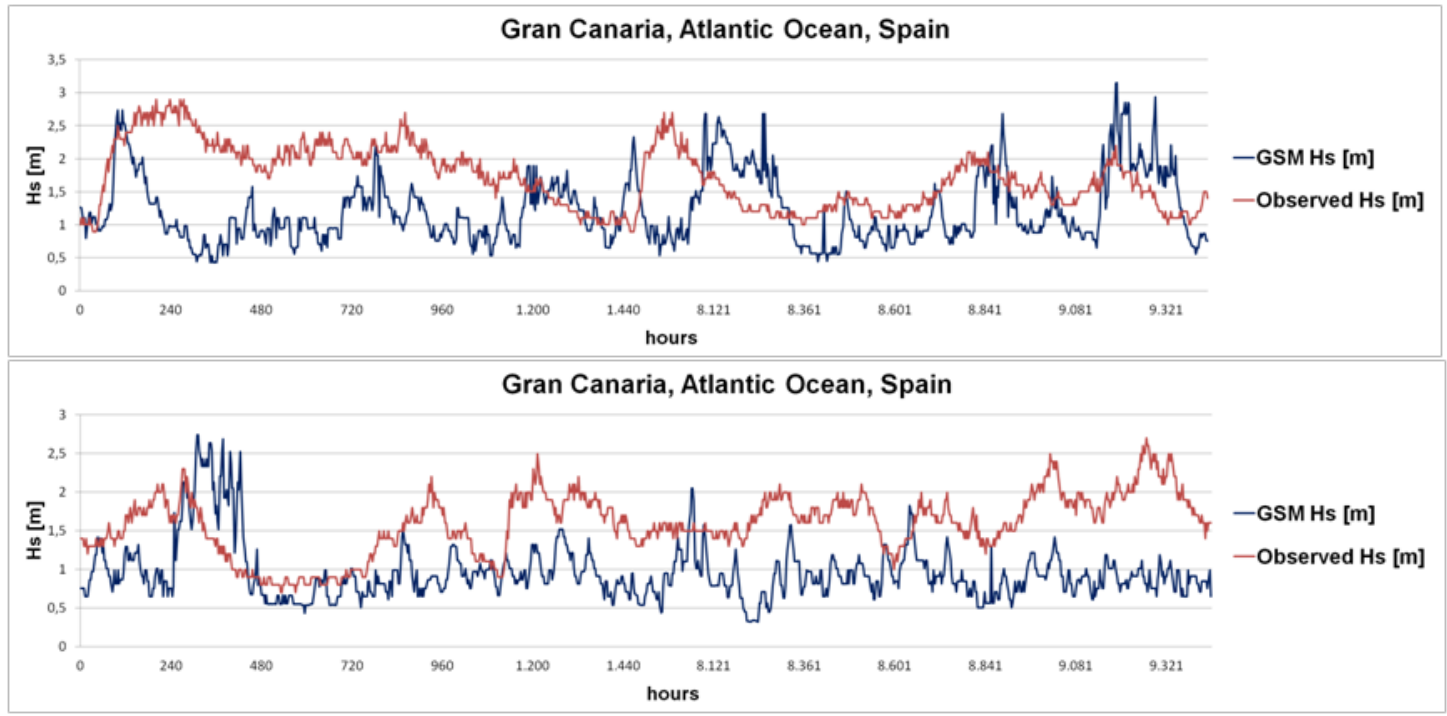

Fig. 13 - Gran Canaria, Atlantic Ocean, Spain: Observed (-) vs. shifted (-), $H_{S}[\mathrm{~m}]$ values.

The considerable distance between the buoys (more than $1000 \mathrm{~km}$ ) negatively affected the result suggesting the need for an upper geographical limit for the applicability of about a few hundred kilometers. The estimated values of $H_{S}$ present an average difference of $15 \%$ compared to the observed values; in the Mediterranean Sea an average deviation of $8 \%$ was obtained. 


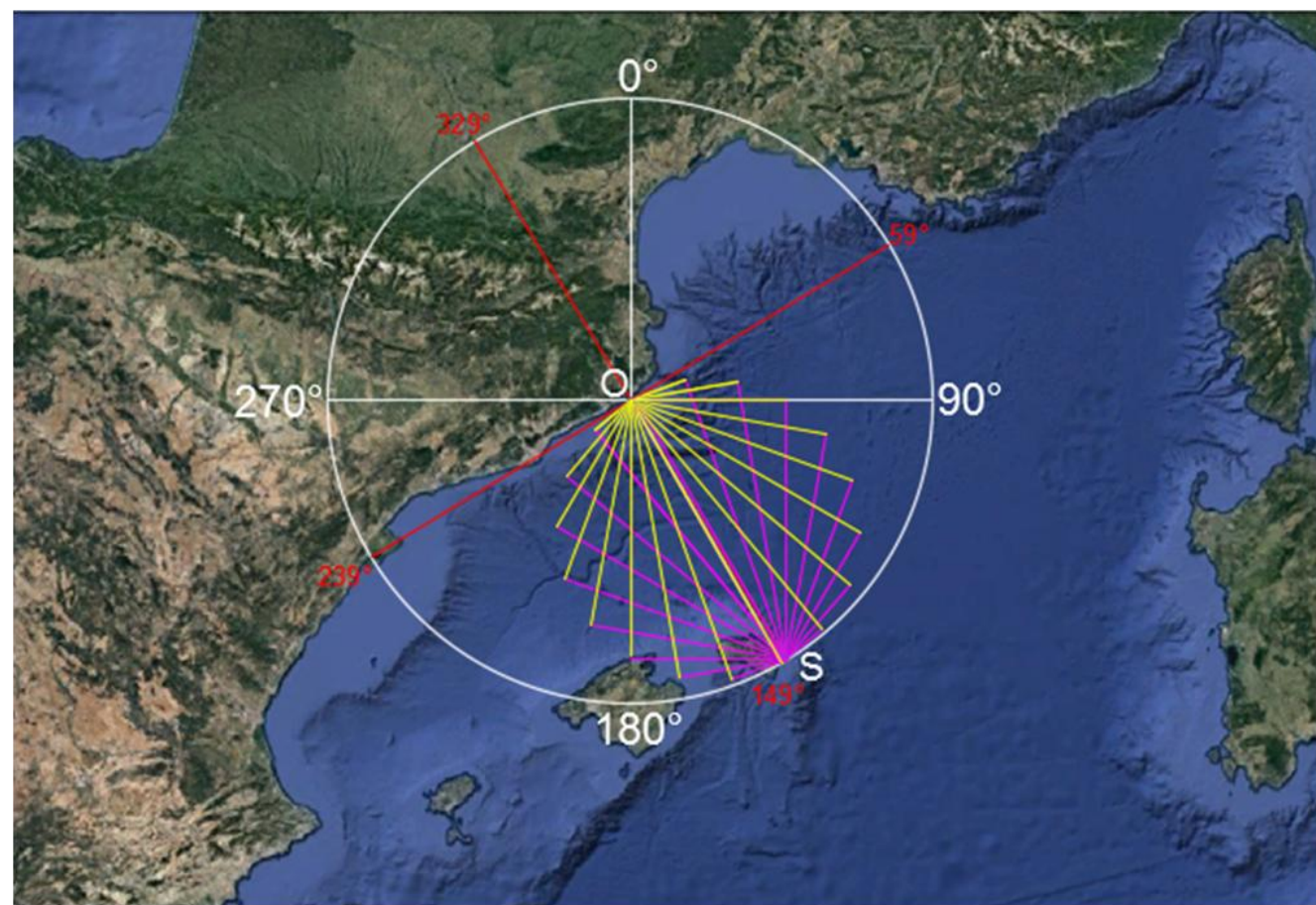

Fig. 14a - Cabo Begur and Mahon, Balearic Sea, Spain: their location and geometrical distance calculation (yellow).

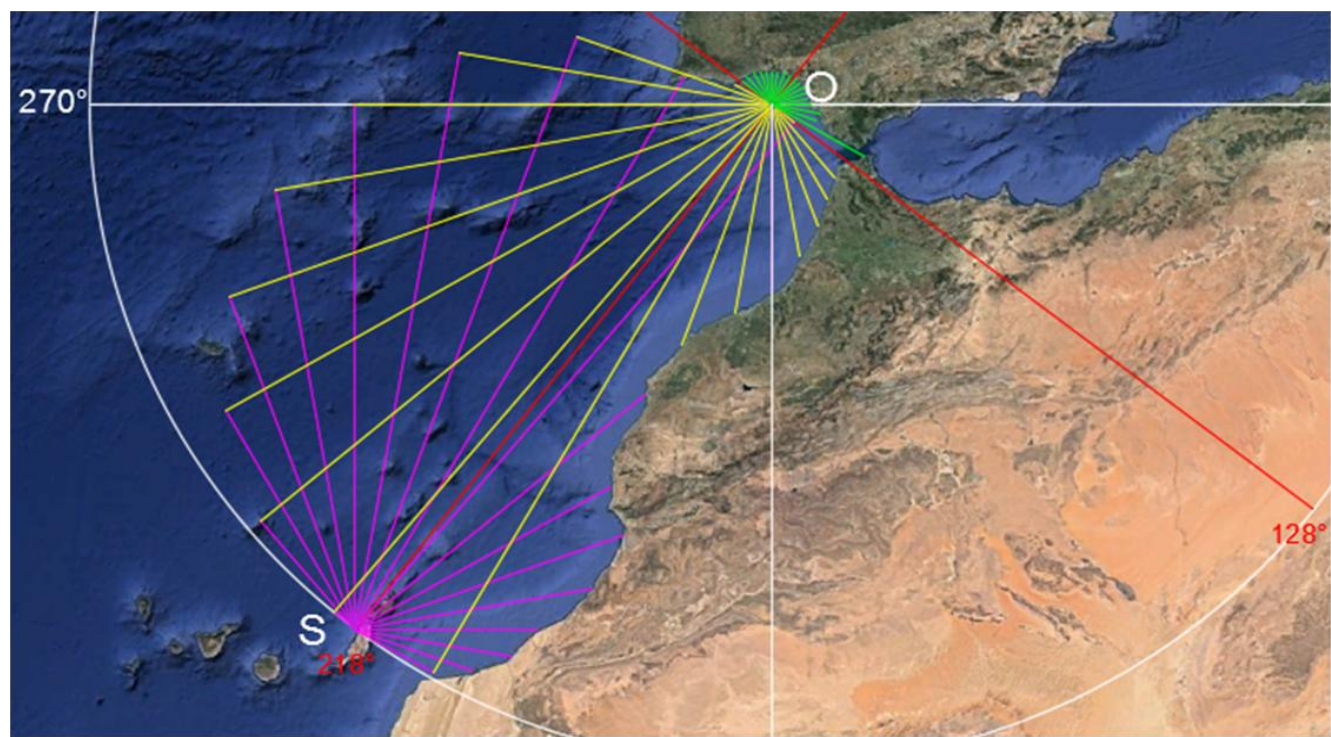

Fig. 14b - Golfo De Cadiz and Gran Canaria, Atlantic Ocean, Spain: their location and geometric distance calculation (yellow).

\subsection{Summary of the results}

Table 1 shows the correlation coefficient obtained for each case study. The distance between real and virtual buoys is given; it can be observed that the closer are the real buoy and virtual buoy locations, the larger is the correlation coefficient between observed and estimated $H_{S}$ values.

The highest values of the correlation coefficient are attained for the cases Capo Spartivento vs. Roccella Ionica (0.84) and Capo Begur vs. Mahon (0.80), while the smallest values are attained for the case Ortona vs. Ancona $(0,33)$ and Golfo De Cadiz vs. Gran Canaria $(0.10)$. The remaining cases present values between 0.64 and 0.69 . As a consequence, it can be said that the correlation shows a tendency to increase with the decreasing distance between the buoys, with the exceptions of Ortona and Ancona, where the coefficient value is the lowest, due to the particular morphological characteristics, and Cabo Begur to Mahon, where we see an opposite situation, thanks to the highly homogeneous sea conditions (Gencarelli et al., 2006). 
Tab. 1 - Correlation coefficient and the distance between the real and virtual buoys for the selected case studies.

\begin{tabular}{|l|c|c|}
\hline \multicolumn{1}{|c|}{ Case study } & $\begin{array}{c}\text { Distance between real } \\
\text { and virtual buoy } \\
{[\mathrm{km}]}\end{array}$ & Correlation coefficient \\
\hline Ponza-Capo Linaro & 150 & 0.69 \\
\hline Ortona-Ancona & 158 & 0.33 \\
\hline Capo Spartivento-Roccella & 60 & 0.84 \\
\hline Crotone-Capo Spartivento & 170 & 0.64 \\
\hline Crotone-Roccella & 110 & 0.68 \\
\hline Cabo Begur-Mahon & 250 & 0.80 \\
\hline Golfo De Cadiz-Gran Canaria & 1280 & 0.10 \\
\hline
\end{tabular}

In the case of Ortona and Ancona, a lower correlation might be due to the particular characteristics of the Adriatic Sea, similar to a straight big lake, with a length of about $800 \mathrm{~km}$ and with a single connection to the Mediterranean Sea at its southern end, resulting in a fetch of smaller length along most of the possible wind directions. For the Golfo of Cadiz and Gran Canaria case, the lack of correlation might be due to the considerable distance between the two buoys (nearly $1000 \mathrm{~km}$ ).

\section{CONCLUSIONS}

The design of a maritime structure and the coastal management (Barbaro, 2007; Romolo et al., 2009; Tomasicchio et al., 2011, 2015; Barbaro 2016) requires the reliable assessment of the offshore and inshore wave climate.

The present paper proposes a new method able to accurately estimate the wave climate in locations where there are no measuring buoys. The method offers advantages compared to the traditional ones which are currently used; in fact, among the others, it offers the advantage of being suitable for any sea condition: duration/fetch limited or fully arisen.

The method is a "Geographical Shifting Model" (GSM) of the wave characteristics. It is based on the JONSWAP method (USACE, 1984) and on the assumption of initial homogeneous anemometric conditions between the two considered locations, the first where a real wave buoy is and the second where a virtual buoy is displaced. The method takes into account the geographical distance between the two locations and considers the dependence of the characteristics of the sea state from the conditions of wave development (a fully arisen or limited sea due to length of fetch or storm duration). In particular, in presence of a fully arisen or limited sea at both locations, the calculation of $H_{S}$ at the virtual buoy assumes the sea condition at the real buoy location. If the sea state results different at the two locations, the average of the two values of $H_{S}$ at the two locations is a reliable estimate.

The proposed method has been verified at several locations of the Mediterranean Sea and Atlantic Ocean. The largest values of the correlation coefficient have been found for the case of Capo Spartivento vs. Roccella (0.84) and Capo Begur vs. Mahon (0.80), while the lowest values have been found for the case Ortona vs. Ancona (0.33) and Golfo De Cadiz vs. Canaria (0.10). For all the remaining cases, the correlation coefficient has been found between 0.64 and 0.69 . The analysis of the results has shown that the correlation coefficient presents a tendency to increase with a decreasing distance between the real buoy and the virtual buoy, with exceptions represented by Ortona and Ancona, presenting the lowest value, and from Capo Begur and Mahon. For the case of Ortona and Ancona, a smaller correlation might be due to the particular characteristics of the Adriatic Sea.

For the Golfo of Cadiz vs. Gran Canaria case, the lack of correlation might be due to the considerable distance between the two buoys (nearly $1000 \mathrm{~km}$ ). The best range of applicability of the method resulted to be within a radius of some tens of kilometers from the place of origin (about 60 $\mathrm{km}$ ), a distance that can also double up without significant loss of quality. 


\section{REFERENCES}

Barbaro G. (2007) A new expression for the direct calculation of the maximum wave force on vertical cylinders, Ocean Engineering, 34, 1706-1710 Elsevier.

Barbaro G. (2016) Master Plan of the solutions for mitigating the risk of coastal erosion in Calabria (Italy), a case study", Ocean and coastal management, 132, 24-35.

Barbaro, G., Foti, G. (2013) Shoreline behind a breakwater: comparison between theoretical models and field measurements for the Reggio Calabria sea. Journal of Coastal Research, 29(1), pp. 216224.

Cavaleri L., Sclavo M. (2006) The calibration of wind and wave model data in the Mediterranean Sea. Coastal Engineering, 53 (7), pp. 613-627.

Contini P., De Girolamo P. (1998) Impatto morfologico di opere a mare: casi di studio. Proc. VIII AIOM conference, Lerici, 28-29 may (in Italian)

Donelan, M.A. (1980). Similarity Theory Applied tot he Forecasting of Wave Heights, Periods, and Directions. Proceeding of the Canadian Costal Conference, National Research Council, Canada, pp. 47-61.

Gencarelli, R., Tomasicchio, G.R., Veltri, P. (2006). Wave height long term prediction based on the use of the spread parameter. Proceedings $30^{\text {th }}$ International Conference on Coastal Engineering, San Diego, ASCE, 701-713.

Goda, Y. (2004). Spread parameter of extreme wave height distribution for performance-based design of maritime structures. J. Waterway, Port, Ocean and Coastal Eng., vol. 130, No. 1, pp. 29-38, ASCE.

Hasselmann, K. (1973). Measutements of Wind-Wave Growth and Swell Decay during the Joint North Sea Wave Project (JONSWAP). German Hydrographic Journal, Published by the German Hydrographic Institute.

Hasselmann, K. (1975). A parametric wave prediction model. Journal of Physical Oceanography, 6, pp. 200-228.

Kamphuis, J. W. (2000). Introduction to coastal engineering and management. Advanced Series on Coastal Engineering - Volume 16, World Scientific.

Romolo A., Malara G., Barbaro G. and Arena F. (2009), An analytical approach for the calculation of random wave forces on submerged tunnels, Applied Ocean Research, 31, pp 31-36.

Smith, J. M. (1991), Wind-Wave Generation on Restricted Fetches. Coastal Engineering Center, Department of the Army, Waterways Experiments Station, Corps of Engineers.

Tomasicchio GR, D’Alessandro F. and Barbaro G., (2011) Composite modelling for large-scale experiments on wave-dune interaction. Journal of Hydraulic Research, 49, pp. 15-19.

Tomasicchio GR, D’Alessandro F., Barbaro G., Musci E. and De Giosa, T.M. (2015) Longshore transport at shingle beaches: an indipendent verification of the general model. Coastal Engineering, 104, pp. 69-75

USACE (1984). Shore Protection Manual, 1984, 4th ed., US Army Engineer Waterways Experiment Station, Coastal Engineering Research Center, US Government Printing Office, Washington, DC. 